\title{
JAK1 Inhibitor INCB052793
}

National Cancer Institute

\section{Source}

National Cancer Institute. AK1 Inhibitor INCB052793. NCI Thesaurus. Code C118629.

An orally bioavailable inhibitor of Janus-associated kinase 1 (JAK1), with potential

antineoplastic activity. Upon oral administration, INCB052793 specifically binds to and inhibits the phosphorylation of JAK1, which interferes with JAK-dependent signaling and may lead to an inhibition of cellular proliferation in JAK1-overexpressing tumor cells. The JAK-STAT (signal transducer and activator of transcription) signaling pathway is a major mediator of cytokine activity and is often dysregulated in a variety of tumor cell types. 